\section{Herbal history}

An Illustrated History of the Herbals. By F. J. Anderson. Pp. 270. (Columbia University Press: New York, 1977.) \$21.20.

A HERBAL is a book about the plants and other materials used in medicine up to the middle of the seventeenth century, though their use lingered on after that. $A n$ Illustrated History of the Herbals is an interesting account of these works (in many cases compilations) which most people never have a chance of seeing, locked up as they are in libraries. The words 'locked up' are used advisedly, as herbals are among the most precious of all books, not only because of their rarity but because they include some of the earliest examples of the printer's art.

Many of us have had recourse to Gerard or Parkinson at some time or other, but few go further back, even to Turner or Fuchs, though we may be aware of the earlier works and have access to some of them. Mr Anderson's book is all the more valuable for opening up this lost world, alien though it may be. Little of what was written in the mediaeval herbals relied on direct observation and there is a good deal of mumbo-jumbo, not that either of these defects has entirely disappeared from all modern books on medicinal plants. Indeed, it is salutory and somewhat chastening to note how little has changed in some respects: though astrology is no longer called in to help with the times for

\section{Function of zoological illustration}

Zoological Illustration: An Essay Towards a History of Printed Zoological Pictures. By David Knight. Pp. 204. (William Dawson: Folkestone, UK, 1977.) $£ 10$.

IN some natural sciences, results and ideas can be communicated successfully in wholly verbal or mathematical languages, and the absence of illustrations may even be taken as a mark of the science's maturity. In other sciences, visual representations remain indispensible, however 'mature' the field becomes. But their cognitive and social functions, and therefore their style, may change greatly in the course of time. For example, ostensibly theory-free and 'realistic' pictures are of ten replaced by increasingly diagrammatic representations, which can only be interpreted by those trained in the visual conventions of the discipline: the highly abstract diagrams of organic chemistry and tectonic geology are

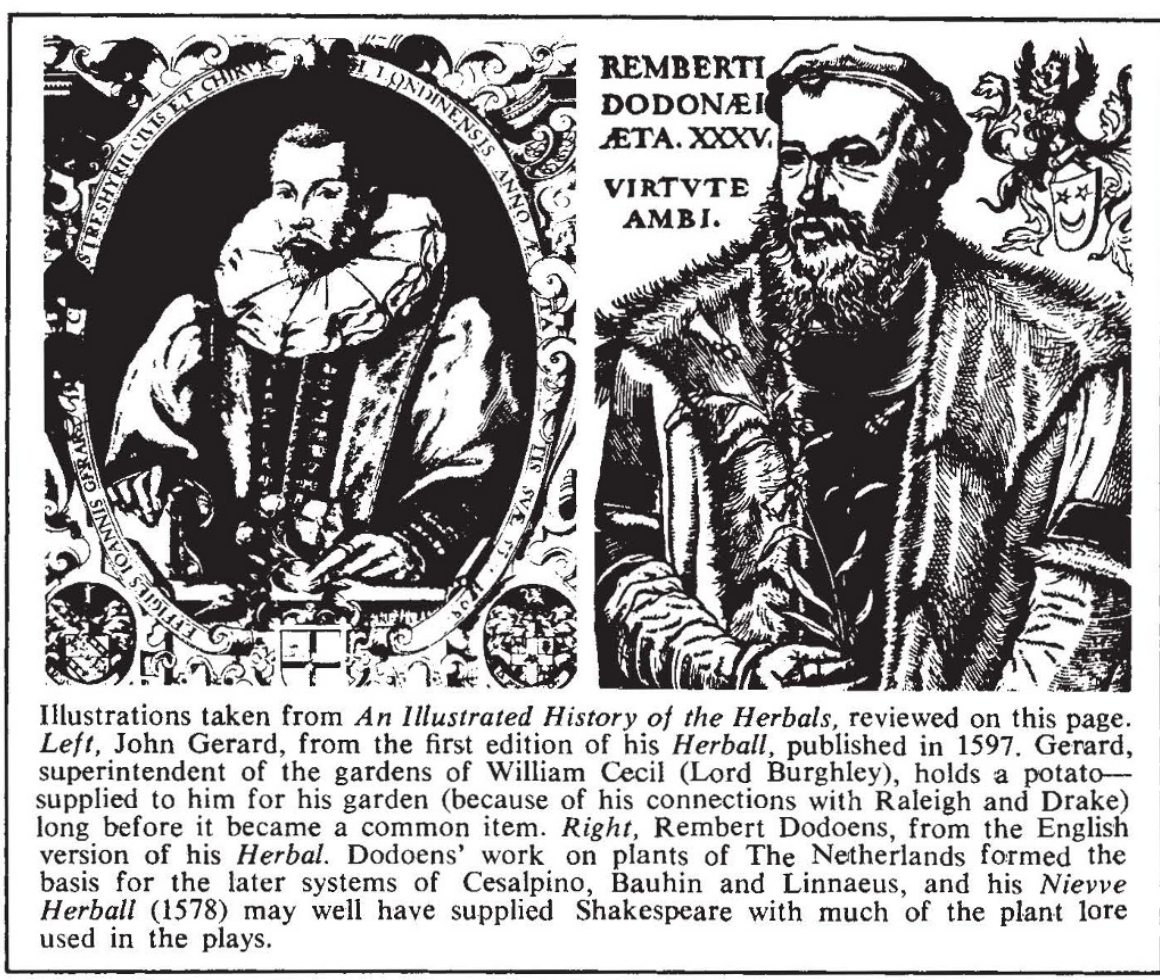

seed sowing or to diagnose illness, many people still say they believe in horoscopes!

The gradual realisation that the plants mentioned in Dioscorides were not necessarily the same as those in northern Europe, the various attempts at a system of classification, and the increase in scientific knowledge, these may all be seen in the herbals as they came to an end, to be replaced by works on botany and separated from medicine; the science of

good examples. At the same time, more 'realistic' illustrations may continue to flourish as means of visual communication on a more popular level, or to satisfy less cognitive and more aesthetic demands.

The history of zoological illustration would make a fascinating case-study of the changing role and style of visual communication in a science in which pictures of some kind are virtually indispensable. It is sad that Knight's book misses this opportunity. He rightly poses the question, "what function in science have zoological illustrations played at different times?", but the answers given are too diffuse to be of much use. Some of the best insights, such as the comment that "one cannot draw what one does not understand", are given as throw-away passing remarks, instead of providing an interpretative framework for the whole work.

The text contains many interesting items of information, but its style can only be described as rambling and repetitive. Most surprisingly for a work on this subject, the illustrations reproduced are not tied into the text by any cross-referencing. There is a useful botany has its roots in the past of the herbals, and owes them a great debt.

$\mathrm{Mr}$ Anderson's book is well produced and delightfully illustrated, but some errors have crept into the captions, which seem to be rather less scholarly in style and content than the rest of this charming book.

Rosemary Angel

Rosemary Angel is Head of the Museums Division at the Royal Botanic Gardens, Kew, UK.

survey of the various techniques of reproduction, but their effects on visual communication are not evaluated systematically, and the illustrative examples are not identified in the captions as 'woodcut', 'copper engraving', 'lithograph', and so on.

The illustrations surveyed range in time from the beginnings of printing to about the mid-nineteenth century (plus one incongruous eleotron micrograph), with a heavy emphasis on the decades around 1800 and on the more ornamental or 'coffee-table' kind of book. Both text and illustrations are also rather strongly weighted towards British sources and the history of British science.

As the aesthetic impact of the great nineteenth-century colour-plate books is rightly emphasised in the text, it is sad that the reader is given only blackand-white reproductions of them, and rather muddy ones at that; surely at the price demanded the publishers could have allowed at least one coloured plate for a frontispiece.

Martin Rudwick

Martin Rudwick is Professor of the History of Science at the Free University. Amsterdam, The Netherlands. 